\title{
Characteristics of Timbers Dried Using Kiln Drying and Radio Frequency- Vacuum Drying Systems
}

\author{
Zairul Amin Rabidin ${ }^{1}$, Gan Kee Seng ${ }^{1}$ and Mohd Jamil Abdul Wahab ${ }^{2}$ \\ ${ }^{1}$ Wood Drying Laboratory, Forest Research Institute Malaysia, 52109 Kepong, Selangor Darul Ehsan, Malaysia \\ ${ }^{2}$ Timber Engineering Laboratory, Forest Research Institute Malaysia, 52109 Kepong, Selangor Darul Ehsan, Malaysia
}

\begin{abstract}
Heavy hardwoods are difficult-to-dry timbers as they are prone to checking and internal stresses when dried using a conventional kiln drying system. These timbers are usually dried naturally to reach $15 \%$ to $19 \%$ moisture content with an acceptable defects. Besides long drying time, timbers at these moisture contents are not suitable for indoor applications since they will further dry and causing, for example, jointing and lamination failures. Drying to a lower moisture content could only be achieved in artificial drying kilns such as conventional kiln, dehumidification kiln, solar kiln, radio frequency-vacuum, etc. The objective of this study was to evaluate the characteristics of $30 \mathrm{~mm}$ and $50 \mathrm{~mm}$ thick kekatong (Cynometra spp.) timber dried using kiln drying (KD) and radio frequency-vacuum drying (RFV) system. The investigation involved drying time, moisture content (MC) variations between and within boards, drying defects, shrinkage, and drying stress. Drying defects include checks (surface, end, and internal checks) and warping (bowing, cuping, spring, and twisting). The results showed that RFV drying time was reduced to $50 \%$ compared to the KD. RFV dried boards demonstrated a more uniform MC between and within boards. Shrinkage in width and thickness, as well as tangential/radial and volumetric shrinkages were substantially less in RFV boards. The amount of cupping, bowing and spring were very low and negligible in all drying runs. There was no twisting observed in all drying methods. The number of stress-free RFV board was higher than KD. With proper procedure, the RFV technology could be used for drying heavy hardwoods which are difficult to dry in conventional kilns due to excessive drying times and degradation.
\end{abstract}

\section{Introduction}

Freshly sawn timbers have to be dried before they can be efficiently processed and used. Timber which has not been dried will gradually dry during service. Therefore, the primary reason for drying of wood is to reduce dimensional changes. Excessive dimensional changes will cause distortion and checking in wood, causing both appearance and structural issues in furniture and other wooden products. To minimize extreme changes in $\mathrm{MC}$, and subsequently restrict the movement of wood in service, wood should be dried to its equilibrium moisture content. Timbers for furniture and other interior woodwork should be dried to a targeted MC of 15 to $19 \%$ (depending on the timber species), which can be achieved by air drying. Timbers in air-conditioned environment should be dried artificially in a kiln to $12 \%$ MC. Although air drying is the cheapest method of drying timber, it is a long process and the MC could not be reduced to $12 \%$.

The common method of drying timber to $12 \% \mathrm{MC}$ is using the conventional kiln drying system (KD). Generally, light and medium hardwoods are easy to dry with an acceptable degrade [1]. However, drying heavy hardwoods, especially of the thicker boards, is difficult since the timber is susceptible to excessive degrade and take much longer drying time [2].

Previous studies indicated that thick and refractory timbers can be successfully dried using radio frequencyvacuum (RFV) drying system which may be difficult to dry when using $\mathrm{KD}[2,3]$. The advantages of employing $\mathrm{RF}$ heating are rapid and fairly uniform heat transfer often to solidly stacked timbers, high drying rates, and less drying defects such as case-hardening and oxidative discoloration of the wood $[4,5,6,7)$. [3] also reported that $30 \mathrm{~mm}$ mixed oak species can be dried in RFV kiln from green to $8 \% \mathrm{MC}$ in 65 hours compared to 42 days for kiln drying. According to [8], drying sugi boxed-heart timber in RF after kiln drying to $20 \% \mathrm{MC}$ improved the drying rate and reduced surface checks.

The objective of this study is to assess the drying characteristics of heavy hardwood timbers of two different thicknesses (30 and $55 \mathrm{~mm}$ thick) dried using conventional kiln drying and radio frequency-vacuum drying systems.

\section{Materials and methods}

\subsection{Preparation of samples}


Two kekatong logs were sawn into $30 \mathrm{~mm} \times 120 \mathrm{~mm}$ and $55 \mathrm{~mm} \times 120 \mathrm{~mm}$ according to cutting pattern as shown in Figure 1. Flat sawn boards, or tangential cut, was used because this cutting is easier or cheaper to produce and is susceptible to deformation during drying. Each board then was cut into $990 \mathrm{~mm}$ and 1,700 mm long which was the length required for $\mathrm{KD}$ and $\mathrm{RFV}$, respectively. Two $25 \mathrm{~mm}$ thick strips were cut between samples, $100 \mathrm{~mm}$ from both ends, for estimating $\mathrm{MC}$ for each sample at time of sawing. Samples measuring $20 \mathrm{~mm}$ x $20 \mathrm{~mm}$ x 20 $\mathrm{mm}$ were obtained from each logs for determination of moisture content and density variations in cross section. Initial weight of each sample was weighed and its ovendry weight was estimated in accordance with [1]. Samples for KD were end-coated with bituminous paint in order to minimize effect of end drying.

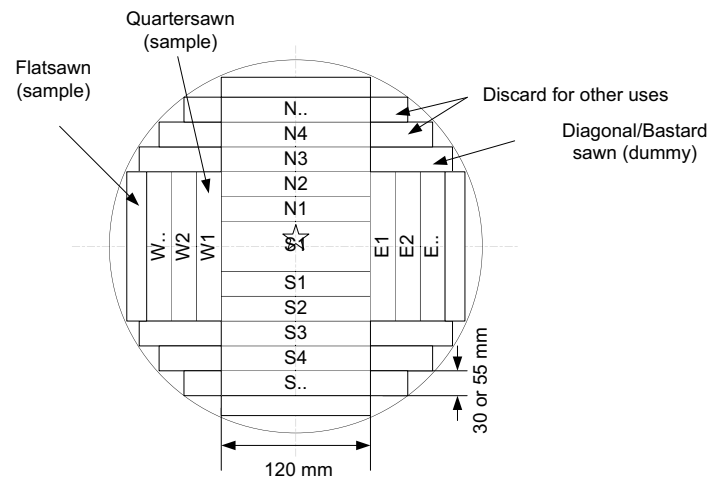

Figure 1. Sawing pattern of a $\log (E=E a s t, N=N o r t h, W=W e s t$, $\mathrm{S}=$ South).

\subsection{Kiln drying}

Drying was conducted in a $0.21 \mathrm{~m}^{3}$ capacity experimental-scale conventional kiln drying. Drying condition was controlled by setting the dry-bulb temperature and the wet-bulb temperature. Humidity was provided by steam and controlled using an automatic damper during drying. Heat was supplied by passing steam through heating coils. Air flow through the stack was provided by the fan located at one side of the kiln with air velocity of $1.5 \mathrm{~m} / \mathrm{s}$. The samples were stacked on $25 \mathrm{~mm}$ by $25 \mathrm{~mm}$ stickers. The stacks were restrained by placing iron block on top of the stack to minimize warping. Drying condition was set according to Table 1. Drying was conducted in different batch for each thickness. High steaming was provided during drying to reduce surface checking, 24 hours in the initial stage of drying and 4 hours for every 2 days.

Table 1. Kiln drying schedule.

\begin{tabular}{|c|c|c|c|c|}
\hline $\begin{array}{c}\text { MC } \\
(\%)\end{array}$ & $\begin{array}{c}\text { DBT } \\
(\mathbf{\%})\end{array}$ & $\begin{array}{c}\text { WBT } \\
(\mathbf{})\end{array}$ & $\begin{array}{c}\text { RH } \\
(\mathbf{\%})\end{array}$ & $\begin{array}{c}\text { EMC } \\
(\mathbf{\%})\end{array}$ \\
\hline Starting & 40.5 & 40.5 & & \\
\hline & 40.5 & 40 & & \\
\hline & 40.5 & 39.5 & & \\
\hline Green & 40.5 & 39 & 90 & 19.8 \\
\hline 60 & 40.5 & 38 & 85 & 16.9 \\
\hline 60 & 43.5 & 40 & 80 & 14.9 \\
\hline 40 & 43.5 & 39 & 75 & 13.3 \\
\hline 35 & 46 & 40.5 & 70 & 12.2 \\
\hline
\end{tabular}

$\mathrm{DBT}=$ dry bulb temperature $\mathrm{RH}=$ relative humidity

$\mathrm{WBT}=$ dry bulb temperature $\mathrm{EMC}=$ equilibrium $\mathrm{MC}$

\subsection{Radio frequency-vacuum drying}

Drying was carried out in an experimental-scale RFV dryer of $0.54 \mathrm{~m}^{3}$ capacity. RF generator operates at a fixed frequency of $6.7 \mathrm{Mhz}$ with maximum output $6 \mathrm{~kW}$ at a maximum electrode voltage of $7.3 \mathrm{kV}$. The samples were stacked in the drying chamber without stickers between three $1.5 \mathrm{~mm}$ thick aluminium plates. Drying was conducted under continuous mode of heating with input current to the RF generator was set to $0.4 \mathrm{~A}$ and voltage of $\mathrm{HFV}$ tube set at $5.5 \mathrm{kV}$. Heating temperature and pressure were set to $40^{\circ} \mathrm{C}$ and 50 torr, lowering the boiling point of water to approximately $38^{\circ} \mathrm{C}$. During drying process, sample boards were weighed every two days until the $\mathrm{MC}$ of between 10 to $14 \%$ is reached.

\subsection{Drying quality}

The following drying characteristics were investigated in this study:

- Drying time.

- Moisture content variation within and between boards.

- Shrinkage of boards in width and thickness, determined by measuring its dimension before and after drying.

- Cupping, bowing, and spring, measured on each sample before and after drying by measuring deflection from a straight line between two ends.

- Twisting, quantified by holding three corners of the lumber against a flat surface and the rise in the fourth corner was measured.

- The residual drying stress (casehardening), evaluated by cutting $30 \mathrm{~mm}$ thick sections into three equal sized prongs and the central portion were removed as described by [9]. After 24 hours, the severity of casehardening, given by degree of turning in, was evaluated and classified into four classes, namely not casehardened, slightly casehardened, casehardened and reverse casehardened [9].

- Surface checks and end checks were assessed by estimating the percentage of checked area.

\section{Results and discussion}

The physical properties and drying characteristics of 30 $\mathrm{mm}$ and 55 thick kekatong boards dried using $\mathrm{KD}$ and RFV system are summarized in Table 2 and Table 3, respectively.

Table 2. Density and moisture content of kekatong.

\begin{tabular}{|l|c|c|c|c|}
\hline & $\begin{array}{c}\text { Green } \\
\text { density } \\
\left(\mathbf{k g} / \mathbf{m}^{\mathbf{3}}\right)\end{array}$ & $\begin{array}{c}\text { Oven-dry } \\
\mathbf{d e n s i t y} \\
\left(\mathbf{k g} / \mathbf{m}^{\mathbf{3}}\right)\end{array}$ & $\begin{array}{c}\text { Basic } \\
\mathbf{d e n s i t y} \\
\left(\mathbf{k g} / \mathbf{m}^{\mathbf{3}}\right)\end{array}$ & $\begin{array}{c}\text { MC } \\
\mathbf{( \% )}\end{array}$ \\
\hline Mean & 1165 & 970 & 821 & 42 \\
\hline Min & 863 & 822 & 708 & 21 \\
\hline Max & 1425 & 1189 & 895 & 59 \\
\hline SD & 117 & 111 & 38 & 11 \\
\hline
\end{tabular}


Table 3. Summary of drying characteristics of kekatong.

\begin{tabular}{|c|c|c|c|c|c|}
\hline \multicolumn{2}{|c|}{ Characteristics } & \multicolumn{2}{|c|}{ Kiln } & \multicolumn{2}{|c|}{ RFV } \\
\hline Thickness (mm) & & 30 & 55 & 30 & 55 \\
\hline Drying time (day) & & 14.2 & 27.3 & 6.7 & 16.1 \\
\hline Initial MC (\%) & & $34.3(5.4)$ & $39.0(9.6)$ & $35.0(3.4)$ & $39.5(6.7)$ \\
\hline Final MC $(\%)$ & & $10.2(1.4)$ & $16.2(2.39)$ & $13.3(0.9)$ & $13.9(2.0)$ \\
\hline \multirow{2}{*}{$\begin{array}{l}\text { MC variation within } \\
\text { boards }\end{array}$} & Inner part MC (\%) & $9.5(1.3)$ & $14.8(1.4)$ & $13.2(0.9)$ & $11.4(2.1)$ \\
\hline & Outer part MC $(\%)$ & $10.5(2.8)$ & $18.8(3.7)$ & $13.2(1.1)$ & $14.4(2.3)$ \\
\hline \multirow[t]{4}{*}{ Shrinkage } & Tangential (\%) & $6.4(0.9)$ & $6.9(0.8)$ & $4.7(0.8)$ & $4.6(1.3)$ \\
\hline & Radial shrinkage (\%) & $3.3(0.9)$ & $3.5(0.8)$ & $2.8(0.9)$ & $3.0(0.7)$ \\
\hline & $\mathrm{T} / \mathrm{R}(\%)$ & $2.1(0.7)$ & $2.2(0.4)$ & $1.5(0.6)$ & $1.6(0.5)$ \\
\hline & Volumetric shrinkage $(\%)$ & $9.5(1.0)$ & $9.5(1.1)$ & $7.4(1.4)$ & $7.4(1.5)$ \\
\hline \multirow[t]{6}{*}{ Surface checks } & $\begin{array}{l}\text { No. of boards with checks/Total } \\
\text { boards }\end{array}$ & $21 / 60$ & $20 / 20$ & $25 / 32$ & $15 / 16$ \\
\hline & Percentage of boards with checks ${ }^{\mathrm{a}}$ & & & & \\
\hline & $\leq 5 \%$ & $88 \%$ & $55 \%$ & $84 \%$ & $100 \%$ \\
\hline & $6 \%$ to $\leq 10 \%$ & $0 \%$ & $5 \%$ & $13 \%$ & $0 \%$ \\
\hline & $11 \%$ to $\leq 15 \%$ & $2 \%$ & $20 \%$ & $0 \%$ & $0 \%$ \\
\hline & $>15 \%$ & $10 \%$ & $20 \%$ & $3 \%$ & $0 \%$ \\
\hline \multirow[t]{6}{*}{ End checks } & $\begin{array}{l}\text { No. of boards with checks/ Total } \\
\text { boards }\end{array}$ & $11 / 60$ & $20 / 20$ & $31 / 32$ & $13 / 16$ \\
\hline & Percentage of boards with checks ${ }^{\mathrm{a}}$ & & & & \\
\hline & $\leq 5 \%$ & $100 \%$ & $55 \%$ & $80 \%$ & $100 \%$ \\
\hline & $6 \%$ to $\leq 10 \%$ & $0 \%$ & $35 \%$ & $19 \%$ & $0 \%$ \\
\hline & $11 \%$ to $\leq 15 \%$ & $0 \%$ & $7 \%$ & $1 \%$ & $0 \%$ \\
\hline & $>15 \%$ & $0 \%$ & $3 \%$ & $\%$ & $0 \%$ \\
\hline $\begin{array}{l}\text { Internal checks } \\
\text { (honeycomb) }\end{array}$ & Boards with checks $(\%)$ & $0 \%$ & $0 \%$ & $0 \%$ & $0 \%$ \\
\hline Collapse & Boards with checks $(\%)$ & $0 \%$ & $0 \%$ & $0 \%$ & $0 \%$ \\
\hline \multirow[t]{2}{*}{ Cupping } & No. of boards & $0 / 60$ & $0 / 20$ & $0 / 32$ & $2 / 16$ \\
\hline & Deflection/Width (\%) & 0 & 0 & 0 & 0.1 \\
\hline \multirow[t]{2}{*}{ Bowing } & No. of boards & $13 / 60$ & $3 / 20$ & $15 / 32$ & $5 / 16$ \\
\hline & Deflection/Length (\%) & 0.1 & 0.1 & 0.1 & 0.1 \\
\hline \multirow[t]{2}{*}{ Spring } & No. of boards & $10 / 60$ & $3 / 20$ & $16 / 32$ & $8 / 16$ \\
\hline & Deflection/Length (\%) & 0.1 & 0.1 & 0.1 & 0.1 \\
\hline \multirow[t]{4}{*}{ Drying stress (\%) } & Absent & 74 & 35 & 100 & 90 \\
\hline & Slightly & 7 & 65 & 0 & 10 \\
\hline & Casehardened & 19 & 0 & 0 & 0 \\
\hline & Reversed casehardened & 0 & 0 & 0 & 0 \\
\hline
\end{tabular}

${ }^{a}$ Percentage of surface area with checks

\subsection{Moisture content and density}

The basic density of kekatong was $821 \pm 38 \mathrm{~kg} / \mathrm{m}^{3}$ (Table 2 ). The average air dry density of kekatong at $15 \% \mathrm{MC}$ is between 880 and $1,155 \mathrm{~kg} / \mathrm{m}^{3}$ [10]. The mean green $\mathrm{MC}$ was $42 \pm 11 \%$. The results obtained in this study indicated that kekatong had a low green MC but dense, which could be difficult to dry.

\subsection{Drying time}

Figure 2 shows the drying curve of kekatong. The $30 \mathrm{~mm}$ boards achieved average moisture content of $10.2 \%$ after drying in a kiln for 14.2 days while $55 \mathrm{~mm}$ boards achieved average MC of $16.2 \%$ after 27.3 days. RFV drying time for $30 \mathrm{~mm}$ boards was 6.7 days while $55 \mathrm{~mm}$ boards were dried to $13.9 \% \mathrm{MC}$ in 16.1 days. Drying time of kekatong in RFV was about half of the kiln drying time.

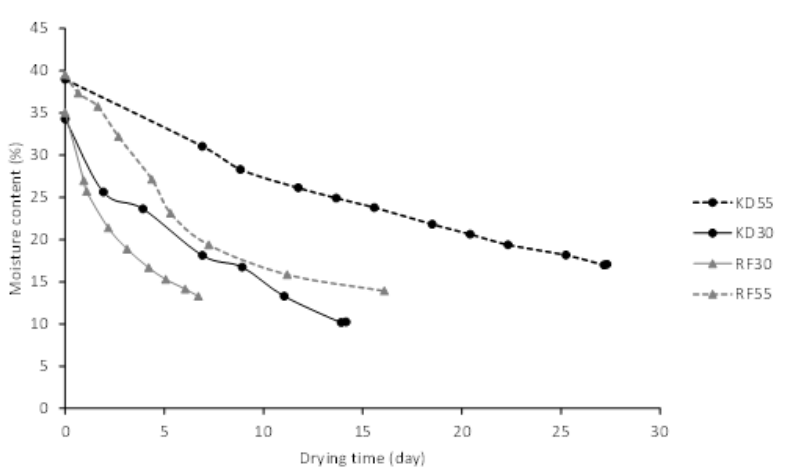

Figure 2. Drying curve of $30 \mathrm{~mm}$ and $55 \mathrm{~mm}$ thick kekatong.

\subsection{Moisture content variation between samples}

Final MC for RFV ranged from 11.2 to 13.9 for $30 \mathrm{~mm}$ and 9.5 to $15.2 \%$ for $55 \mathrm{~mm}$ boards, respectively while for $\mathrm{KD}, \mathrm{MC}$ ranged from 10.1 to $16.2 \%$ (30 mm boards) and 13.3 to 18.7 (55 mm boards). It was observed that large variation in $\mathrm{MC}$ was observed for kiln dried samples and the variation of MC however was reduced in the RFV runs. The percentage boards between 10 to $14 \% \mathrm{MC}$, 
below $10 \% \mathrm{MC}$ and above $14 \%$ is given in Table 4 . RFV had more boards between $10 \%$ and $14 \%$ MC than KD. The variation of MC in RFV drying was reduced by placing the wettest lumbers at the centre of the stack, near to the positive electrode plate before and during drying. In the case of kiln drying, more even MC could be achieved by conditioning treatment at the final stage of drying.

Table 4. Percentage of boards at difference MC range.

\begin{tabular}{|l|c|c|c|c|}
\hline $\begin{array}{c}\text { Final MC } \\
\text { range }\end{array}$ & KD30 & KD55 & RF30 & RF55 \\
\hline$<10 \%$ & 61 & 0 & 0 & 9 \\
\hline $\begin{array}{l}10 \% \text { to } \\
14 \%\end{array}$ & 34 & 15 & 86 & 66 \\
\hline $14 \%$ & 5 & 85 & 14 & 25 \\
\hline
\end{tabular}

\subsection{Moisture content variation within samples}

The MC difference between the outer and inner parts for $30 \mathrm{~mm}$ boards were comparatively low compared to 55 $\mathrm{mm}$ boards for both drying methods. RFV dried samples had relatively lower average inner-outer MC difference than KD with the variation below than $2 \%$. MC difference of up to $7 \%$ were observed in some $55 \mathrm{~mm}$ boards dried using KD. It was also found that a number of $30 \mathrm{~mm}$ boards dried using RFV had a drier inner MC compared to the outer part. This could be due to the fact that RF wave selectively heats the wetter areas in a lumber, which most of the time are in the inner.

\subsection{Shrinkage}

The shrinkage values for 30 and 55 thick boards dried using the same methods were essentially the same. Shrinkage in width (tangential) and thickness (radial) were substantially less for RFV. The shrinkage values for $30 \mathrm{~mm}$ thick boards dried using RFV were reduced to $27 \%$ tangentially and $15 \%$ radially compared to $\mathrm{KD}$ while for $55 \mathrm{~mm}$ thick boards, the reduction were about $33 \%$ and $14 \%$. Both reductions in tangential shrinkage and in radial shrinkage resulted in approximately $30 \%$ less in $\mathrm{T} / \mathrm{R}$ ratio and $22 \%$ less in volumetric shrinkage in the RFV dried boards. The reduction of $T / R$ ratio for RFV dried timber could be primarily contributed by reduction of tangential shrinkage compared to radial shrinkage. [6] reported that, the low $\mathrm{T} / \mathrm{R}$ ratio of $\mathrm{RFV}$ dried wood might be desirable to help prevent warping and checking during drying and improvement in dimensional stability might be expected.

\subsection{Surface checks and end checks}

RFV had substantially less surface and end checks than KD. Thinner boards also had lower checks than thicker boards. In KD30, RF30 and RF55, none of the surface checks were deep enough (over $4 \mathrm{~mm}$ deep) to cause manufacturing problems. It was observed that some surface checks developed in the initial stage of RFV drying stage were closed towards the end of drying
(Figure 3). These surface checks can be easily removed by planing the boards $3 \mathrm{~mm}$ from the surface. However, deep checks were found on about $5 \%$ of the boards in KD55. In all drying run, the end checks were less than 50 $\mathrm{mm}$ long which were not observed after cross cutting 100 $\mathrm{mm}$ from both ends. The lower checks in RF was contributed by the lower drying stress developed due to differential $\mathrm{MC}$ in outer and inner surface. This may also be contributed by reduction in $T+R$ and $T / R$ values in RFV drying compared to kiln drying method. There were no internal checks (honeycomb) and collapse in both drying methods.
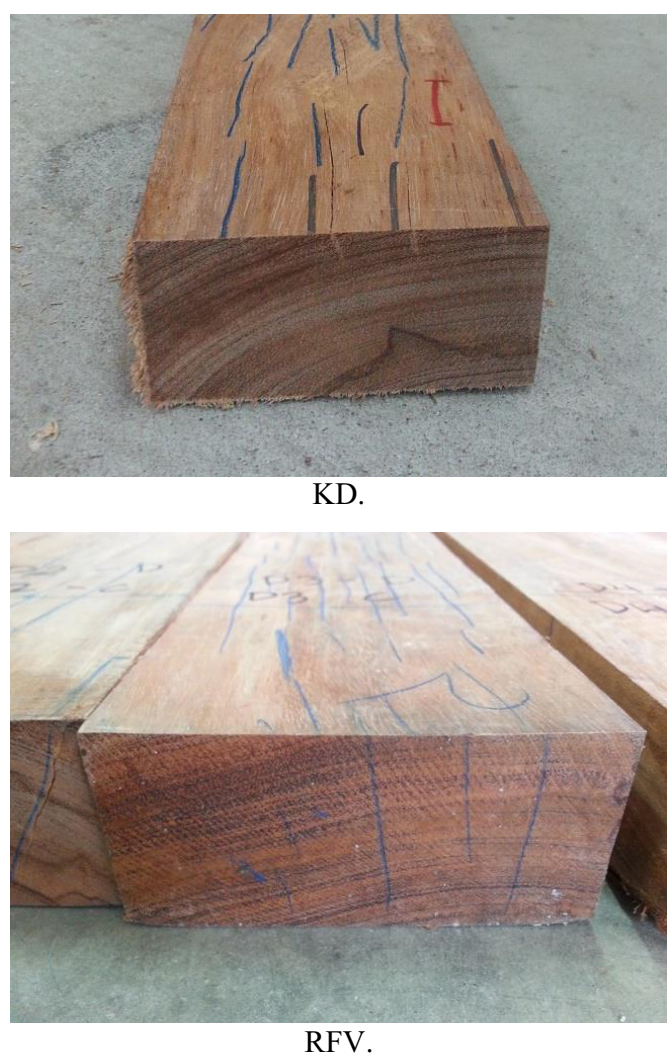

Figure 3. Surface checks and end checks in $55 \mathrm{~mm}$ thick sample

\subsection{Cupping, bowing, spring and twisting}

The amount of cupping, bowing and spring were very low and negligible in all drying run. There was no twisting detected in all drying methods. In this study, distortion due to the differential shrinkage in radial and tangential grain orientations was restrained mechanically by hydraulic pressing during RFV drying and placing a concrete block on top of the timber stack during KD.

\subsection{Drying stress}

The percentage of boards with drying stress were lower in RFV compared with KD (Table 3). This was contributed by a lower moisture gradient across the timber thickness in RFV. Excessive residual drying stresses causes machining problems especially during ripping. 


\section{Conclusions}

Drying kekatong timber using RFV drying system significantly reduced the drying time by $50 \%$ of that using conventional kiln-drying system. The quality of timber in terms of the uniformity of MC, shrinkage, surface- and end-checks, warping (cupping, bowing, spring), and drying stress was better than KD. This study has demonstrated that the RFV drying system may be used not only where quality improvement is possible, but also where kiln drying methods become very slow or inefficient toward the end of drying process. Further investigation should be conducted on improving procedure of drying other refractory and thicker heavy hardwoods including possibility to combine RFV drying with kiln drying to take advantages and limitations of these two drying technologies.

The present study was conducted on heavy hardwood species which is difficult to dry. The results however can be used as a guide for the timber manufacturer to explore the possible use of RFV for drying other timber of different thicknesses. Since the RFV drying system totally uses electricity for generating high frequency wave as well as operating the chiller, vacuum pump and hydraulic press, it is possible to incorporate RFV with $\mathrm{KD}$ in the initial or later stages of drying. Optimizing the drying parameters and improving the permeability of heavy hardwoods are recommended for future study.

\section{Acknowledgement}

The research was financially supported by the Ministry of Science, Technology and Innovation Malaysia (Science Fund Project No. 06-03-10-SF0214). Acknowledgement is due to Tanjong, Jamal, and Ascem for their technical assistance.

\section{References}

1. G.S. Grewal. Kiln drying characteristic of some Malaysian timbers. Timber Trade Leaflet No. 42. Ministry of Primary Industries, Malaysia (1998)
2. S. Avramidis, Liu F. Drying characteristics of thick lumber in a laboratory radio-frequency/vacuum dryer. Drying Technology 12(8): 1963-1981 (1994)

3. R.A. Harris, M.A. Taras. Comparison of moisture content distribution, stress distribution, and shrinkage of red oak lumber dried by a radiofrequency/vacuum drying process and a conventional kiln. For. Prod. J. 34(1): 44-54 (1984)

4. R.A. Harris, A.W.C. Lee. Properties of white pine lumber dried by radiofrequency/ vacuum process and conventional kiln process. Wood and Fib. Sci. 17(4): 549-552 (1985)

5. H.S. Jung, C.D. Eom, B.J. So. Comparison of vacuum drying characteristics of radiata pine timber using different heating methods. Drying Tech. 22(5): 1005-1022 (2004)

6. N. Lee, H. Jung. Comparison of shrinkage, checking, and absorbed energy in impact bending of Korean ash squares dried by a radio-frequency/vacuum process and a conventional kiln. For. Prod. J. 50(2): 69-72 (2000)

7. R.A. Harris. Dimensional stability of red oak and eastern white pine dried by radiofrequency/vacuum and conventional drying process. For. Prod. J. 38(2): 25-26 (1988)

8. J. Piao, N. Fujimoto, Y. Yamamoto, S. Nagata. Development of hybrid kiln drying system with radio frequency heating for the sugi heart timber. Journal of the Faculty of Agriculture, Kyushu University 52(1): 117-121 (2007)

9. W.T. Simpson. Dry Kiln Operator's Manual Handbook AH-188, USDA Forest Service, Forest Products Laboratory: Madison, WI. Pp 11-150 (1991)

10. P.K.B. Menon. Structure and identification of Malayan woods. Revised by S. Ani, S.C. Lim. Malayan Forest Records No. 25. Forest Research Institute Malaysia: Kepong. P. 55 (1993) 